\title{
Optical Biometry Versus Ultrasound Biometry
}

Abd Elkhalek I. Elsaadani, Nermeen M. Badawi, Asmaa Z.A. Elterawy

Department of Ophthalmology, Faculty of Medicine Menoufia University, Menoufia, Egypt

Corresponding author: Asmaa Z.A. Elterawy, Moblie: (+20)01272412287, E-mail: asmaazakaria987@ gmail.com

\section{ABSTRACT}

Background: Implantation of an intraocular lens (IOL) is the gold standard in modern-day cataract surgery. Over the last decade, IOL power calculations have become a focal point of cataract surgery.

Objective: To compare the sensitivity and specification of optical biometry and applanation ultrasound biometry in the measurement of intraocular lens.

Patient and methods: This prospective cohort study was done on 100 eyes from one hundred patients undergoing phacoemulsification with primary intraocular lens implantation. and scheduled for cataract surgery in the Ophthalmology Department of Menoufia University Hospitals and El-Mahalla Ophthalmology Hospital. Fifty eyes of patients were measured by ultrasound measurement (by A-Scan, Group 1) and the other 50 eyes by optical biometry (by IOL Master, Group 2).

Result: in Group 1There were 22 eyes of 22 males (44\%), and 28 eyes of 28 females (56\%) with a mean age was $58.4 \pm 10.13$ years. While, in Group 2, there were 16 eyes of 16 males $(32 \%)$, and 34 eyes of thirty-fourth females $(68 \%)$ and the mean age of the patients in this group was $61.2 \pm 9.25$ years. The mean IOL of the patient in Group I was $(18.86 \pm 2.57)$ with minimum IOL power (16.29) and maximum IOL power (21.43). Whereas, the mean IOL potent ion of the patient in group II was $(20.5 \pm 1.98)$ with minimum IOL power (18.52) and maximum IOL power $(+22.48)$.

Conclusion: We can conclude that IOL measurements performed by using the Zeiss IOL Master, using partial coherence interferometry, resulted that a significantly better IOL power forecast and therefore the refractive result in cataract surgery than Applanation US biometry.

Keywords: Optical Biometry, Ultrasound Biometry, Intraocular lens.

\section{INTRODUCTION}

Intraocular lens (IOL) calculation is an essential step in obtaining the exact target that includes the refractive result and is a critical goal in modern cataract surgery. Several devices and formulas are currently available, allowing the precise IOL precision needed to reach target refraction ${ }^{(\mathbf{1}, \mathbf{2})}$.

To achieve targeted refraction, the axial length (AL), anterior chamber depth (ACD), and corneal radius (K1 and K2) must be completely accurate ${ }^{(3)}$. Axial length measurement (AL) uses the principle of signal reflection to calculate the difference between the numerous ocular structures and the overall length of the eye. The reflection time of the signal from an interface is measured, divided into two, and multiplied by the speed of the signal in the corresponding medium ${ }^{(4)}$. Distance is measured using the rules: distance $=$ speed * time / 2 the transmitting signal can be ultrasonic. Ultrasound biometrics have been the gold standard for decades. A specific crystal embedded in the probe oscillates to create a high-frequency sound wave to the eye. There are two types of ultrasound biometrics

Biometrics of contact type made by applying an ultrasound probe to the cornea; It carries the risk of infection. Immersion-type biometrics require immersion of the probe in a saline-filled shell. A decade ago, optical biometry was established in clinical practice, and over time optical biometry replaced ultrasound biometry as the standard calculation for measuring the axial length of the eye because it is a fast, easy to use, and contact-free method. Optical biometrics use a780 $\mathrm{nm}$ laser diode infrared light to transmit the signal ${ }^{(5)}$. Interface phenomena between the reflected signal and the reference signal and used to determine distances between interfaces.

Previous comparisons between ultrasound and optical biometrics showed equal or better results with ophthalmometric biometrics ${ }^{(6)}$. A recent study concluded that ultrasound biometrics and optical biometrics can be applied interchangeably for IOL calculations ${ }^{(4)}$.

\section{AIM OF THE STUDY}

This study aimed to compare the sensitivity and specification of optical biometry and applanation ultrasound biometry in the measurement of intraocular lens.

\section{PATIENT AND METHODS}

Study Design: This prospective cohort study was done on patients scheduled for cataract surgery in the Ophthalmology Department of Menoufia University hospitals and El-Mahalla Ophthalmology Hospital. The study was conducted on 100 eyes of one hundred patients undergoing phacoemulsification with primary IOL implantation after the purpose of the study was explained to them. 50 eyes of patients will be measured by ultrasound measurement (by A-Scan, Group 1) and the other 50 eyes by optical biometry (by IOL Master, Group 2). 
Ethical consideration: The study was approved by the ethics committee of the department of ophthalmology, faculty of medicine, Menoufia University. Written informed consent was obtained from all patients.

\section{Inclusion criteria:}

Patients have a visually considerable cataract suitable for phacoemulsification and primary implantation of rearward chamber intraocular lens in one or both eyes. Also, Preoperatively, Snellen visual acuity was evaluated and all patients go through a cycloplegics refraction, IOP gauging, slit lamp examination for studying the morphology of cataract and under examination by indirect ophthalmoscopy, as well, spherical equivalent $<-6 \mathrm{D}$ and or Axial Length $<25.0 \mathrm{~mm}$ as measured by Zeiss IOL Master or A-scan biometry, and the patient is willing and able to comply with scheduled visits and other study procedures.

\section{Exclusion criteria:}

Patients history of trauma, Patients have an ophthalmic condition other than cataract that could affect have vision or axial length measurements such as optic neuropathy, age regarding macular retrogression, macular edema, retinal detachment, proliferative diabetic retinopathy, ocular inflammation, retinitis pigmentosa, or glaucoma. Also, corneal opacities or irregularities: previous scarring, dystrophy, and ectasia.

Surgical exclusion criteria: Patients were excluded from the study when the following complications were encountered through surgery: failure to achieve secure 'in-the-bag' placement of the IOL. Also, the use of corneal sutures and multiple operative procedures at the time of IOL implantation. Also, Post-implantation exclusion criteria.

\section{Methods:}

\section{Patient Preparation:}

Patients were submitted to thorough history taking, clinical, examination, and investigations. All the patients underwent: History taking included: age, sex, residence, special habits of the patients or their relatives, main complaint (painless gradual diminution of vision, analysis of the complaint: onset, course, and duration. Also, previous operations, past history of previous ocular surgery, ocular trauma, drug intake, and family history of any ocular disease.

General examination and vital signs and ocular examination included first: anterior segment examination: an examination of the external eye. Second: posterior segment examination: fundus examination patient underwent dilated fundus examination with an indirect ophthalmoscope to detect any abnormalities included: vitreous humor, retina, and optic disc.

The preoperative evaluation: All patients were undergone phacoemulsification and posterior chamber in-the-bag foldable IOL implantation, preoperatively, Snellen visual acuity was appreciating and all patients underwent non-cycloplegic autorefraction and fundus examination, preoperatively, patients underwent autorefraction, keratometry measurement, and axial length measurement, and USG B scan was done in patients where media opacity was dense obscuring fundus visualization.

Third, Assessment from the Axial Length of the eye included: Group I (Ultrasound group, 50 eyes) had axial length measurements by A-scan ultrasound and $\mathrm{K}$ measurements by manual keratometer. A-scanguided biometry is done by an ophthalmic ultrasound scanner. The first step in the prediction of IOL power is an accurate keratometric reading. Next, the axial length was measured using the contact A-scan biometry. The patients were prepared by instillation of one drop of tropicamide (mydriacil) 1\% then one drop of surface anesthesia in the form of benoxinate hydrochloride $0.4 \%$ is dropped into the patient's eye. The data including two keratometric readings and the average axial length plus a constant of IOL were introduced in the calculating program of the Ophthalmic ultrasound scanner.

This procedure of introduction was repeated with the addition of anterior chamber deepness ACD in the form of the Haigis formula. The intraocular lens power was based on the Haigis formula and all patients underwent uncomplicated cataract surgery by phacoemulsification within the bag IOL implantation through an interim clear corneal incision. Group II (IOL Master Group) (50 eyes) had AL and $\mathrm{K}$ measurements with the IOL Master. An axial length (AL) data, keratometric values (Ks), and anterior chamber depth (ACD) were acquired with the IOL Master by an experienced doctor.

\section{The surgery:}

Phacoemulsification surgery was performed through a $2,3 \mathrm{~mm}$. superior limbal clear corneal incision. All patients underwent in-the-bag implantation of the same IOL power which is soft hydrophobic acrylic foldable IOL obtained by each scan. A standard postoperative topical antibiotic and the anti-inflammatory regime was administered. Patients were studied at the following intervals: 1 day after surgery, 1 week after surgery, 6 weeks after surgery, and 3 months. The primary outcome measure of the study was post-operative spherical equivalent. The actual postoperative spherical equivalence (SE) was recorded 3 months following the surgery by an auto-refractor (Topcon AR, Tokyo, Japan).

The IOL Master permitted calculation using Haigis formula (to calculate the strength of the implanted IOL and predicted postoperative spherical equivalent (SE). The mean absolute error (MAE) was calculated for the Haigis formula which represents the difference between actual postoperative SE and the predicted postoperative SE. This is an absolute rate of the numeric error. Postoperative refraction to compare the results. 


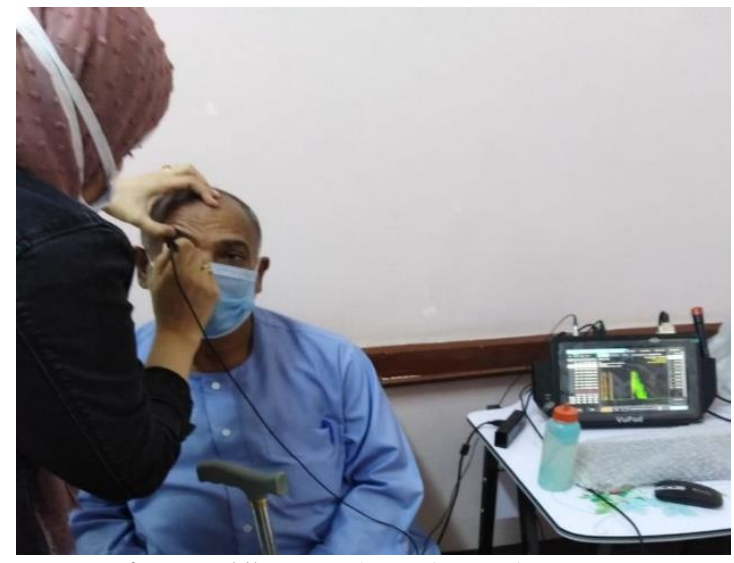

Figure (1): Applanation Biometry.

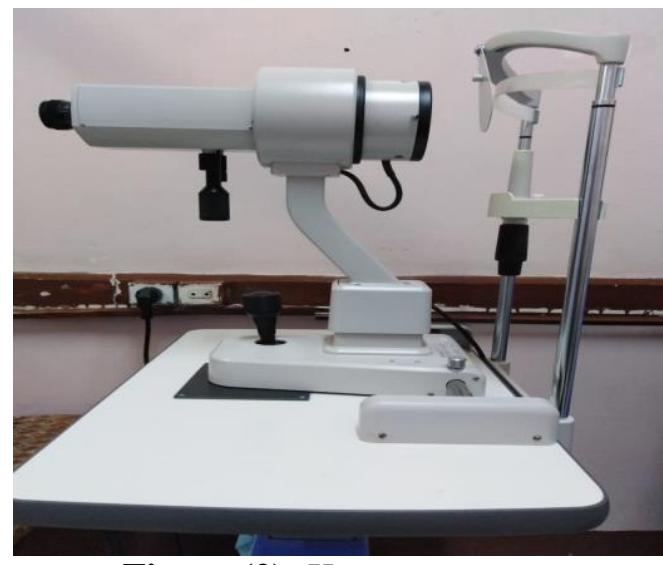

Figure (2): Keratometry.

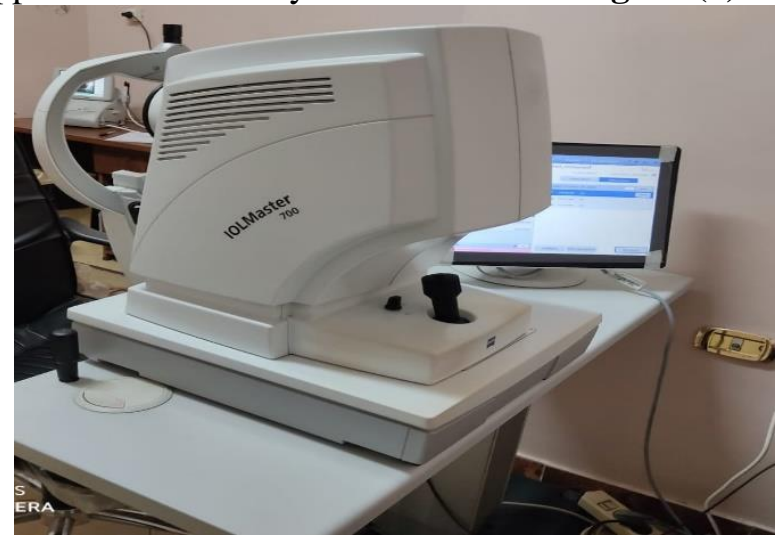

Figure (3): IOL Master 700.

\section{Statistical Methodology}

The data collected were tabulated \& analyzed by SPSS version 15 on IBM compatible computer. Quantitative data were expressed as mean \& standard deviation $(\mathrm{X}+\mathrm{SD})$ and analyzed by applying student $\mathrm{t}-$ test. Qualitative data were expressed as number and percentage (No \& \%), Fisher exact test, Chi-square test, Student t-test, and Spearman's correlation were used. $\mathrm{p}<0.05$ was considered a statistically significant level.

\section{RESULTS}

Group 1 (A-scan ultrasound biometry group) Included 50 eyes subjected to biometry with A-Scan ultrasound biometry. There were 22 eyes of 22 males (44\%), and 28 eyes of 28 females (56\%). And the mean age was 58.4 \pm 10.13 years. While Group 2 (Optical biometry (IOL Master group)) Included 50 eyes subjected to biometry with IOL Master Optical biometry. There were 16 eyes of 16 males (32\%), and 34 eyes of thirty-fourth females (68\%), and the mean age of the patient in this group was $61.2 \pm 9.25$ years.

Also, a total of 100 eyes of one hundred patients were enrolled in our study (eyes in 62 females $(62 \%)$ and eyes in 38 males (38\%). Group I: 22 eyes of 22 males (44\%), and 28 eyes of 28 females $(56 \%)$, and Group II: 16 eyes of 16 males (32\%), and 34 eyes of thirty-fourth females (72\%), as shown in (table 1).

Table (1): Age and sex distribution among both groups

\begin{tabular}{|c|c|c|c|c|c|c|}
\hline \multirow[t]{2}{*}{ Item } & \multicolumn{2}{|c|}{$\begin{array}{c}\text { Group 1 } \\
(\mathrm{n}=\mathbf{5 0})\end{array}$} & \multicolumn{2}{|c|}{$\begin{array}{c}\text { Group } 2 \\
(\mathbf{n}=\mathbf{5 0})\end{array}$} & \multirow[t]{2}{*}{$\mathbf{t}$} & \multirow[t]{2}{*}{ p-value } \\
\hline & $\mathbf{N}$ & $\%$ & $\mathbf{N}$ & $\%$ & & \\
\hline \multicolumn{7}{|l|}{ Age group } \\
\hline $30-40 y$ & 4 & $8.0 \%$ & 2 & $4.0 \%$ & \multirow{4}{*}{7.545} & \multirow{4}{*}{0.056} \\
\hline $40-50 y$ & 6 & $12.0 \%$ & 0 & $0.0 \%$ & & \\
\hline $50-60 y$ & 20 & $40.0 \%$ & 22 & $44.0 \%$ & & \\
\hline$>60 y$ & 20 & $40.0 \%$ & 26 & $52.0 \%$ & & \\
\hline Mean \pm SD & \multicolumn{2}{|c|}{$58.4 \pm 10.13$} & \multicolumn{2}{|c|}{$61.2 \pm 9.25$} & 1.444 & 0.152 \\
\hline \multicolumn{7}{|l|}{ Sex } \\
\hline Male & 22 & $44.0 \%$ & 16 & $32.0 \%$ & \multirow{2}{*}{1.528} & \multirow{2}{*}{0.216} \\
\hline Female & 28 & $56.0 \%$ & 34 & $68.0 \%$ & & \\
\hline
\end{tabular}


The mean axial length of the patient in Group I was $(23.95 \pm 0.89 \mathrm{~mm})$ with minimum axial length $23.02 \mathrm{~mm}$ and maximum axial length $24.84 \mathrm{~mm}$, while, in group, II was $(23.17 \pm 0.64 \mathrm{~mm})$ with minimum axial length $22.53 \mathrm{~mm}$ and maximum axial length $23.81 \mathrm{~mm}$. Also, the mean $\mathrm{k}$ 1reading of the patient in group I was $(44.5 \pm 1.78)$ Diopter. While in group II was $(45.12 \pm 2.01)$ Diopter. Additionally, group I had mean k2 reading of the patients as (44.85 $\pm 1.89)$ Diopter, and group II: had a mean of (44.86 \pm 1.46) Diopter. Group, I had mean k reading of the patient of $(44.6 \pm 1.81)$ Diopter with minimum average $\mathrm{k} 42.01 \mathrm{D}$ and maximum average $\mathrm{k} 46.3 \mathrm{D}$, whereas, group II had mean of $(45 \pm 1.48)$ Diopter with minimum average $\mathrm{k} 42.7 \mathrm{D}$ and maximum average $\mathrm{k} 46.7 \mathrm{D}$, as shown in (table 2).

Table (2): Mean Axial Length and K reading distribution among both groups.

\begin{tabular}{|c|c|c|c|c|}
\hline \multirow{2}{*}{ Item } & $\begin{array}{l}\text { Group 1 } \\
(\mathrm{n}=\mathbf{5 0})\end{array}$ & $\begin{array}{c}\text { Group } 2 \\
(\mathbf{n}=\mathbf{5 0})\end{array}$ & \multirow[t]{2}{*}{$\mathbf{t}$} & \multirow{2}{*}{$\begin{array}{c}\text { p- } \\
\text { value }\end{array}$} \\
\hline & $\mathbf{N}$ & $\%$ & & \\
\hline $\begin{array}{l}\text { Axial } \\
\text { length }\end{array}$ & $\begin{array}{c}23.95 \pm \\
0.89\end{array}$ & $\begin{array}{c}23.17 \pm \\
0.64\end{array}$ & 5.012 & $<0.001 *$ \\
\hline k1 & $\begin{array}{c}44.5 \pm \\
1.78\end{array}$ & $\begin{array}{c}45.12 \pm \\
2.01\end{array}$ & 1.635 & 0.105 \\
\hline k2 & $\begin{array}{c}44.85 \pm \\
1.89\end{array}$ & $\begin{array}{c}44.86 \pm \\
1.46\end{array}$ & 0.032 & 0.975 \\
\hline $\begin{array}{l}\text { Average } \\
\mathbf{k}\end{array}$ & $\begin{array}{c}44.6 \pm \\
1.81\end{array}$ & $45 \pm 1.48$ & 1.218 & 0.226 \\
\hline $\begin{array}{c}\text { ACD } \\
- \text { Range } \\
- \text { Mean } \\
\pm \text { SD }\end{array}$ & $\begin{array}{l}2.84: 3.56 \\
3.2 \pm 0.36\end{array}$ & $\begin{array}{c}2.81: 3.57 \\
3.19 \pm 0.38\end{array}$ & 0.145 & 0.885 \\
\hline
\end{tabular}

ACD: Anterior Chamber Depth

The mean ACD of the patient in group I was $(3.2 \pm 0.36)$ with minimum ACD $2.84 \mathrm{~mm}$ and maximum ACD $3.56 \mathrm{~mm}$, while, in group, II was (3.19 \pm 0.38 ) with minimum ACD $2.81 \mathrm{~mm}$ and maximum ACD $3.57 \mathrm{~mm}$. Also, the mean IOL of the patient in Group I was $(18.86 \pm 2.57)$ with minimum IOL power (16.29) and maximum IOL power (21.43). Whereas, the mean IOL strength of the patient in group II was $(20.5 \pm 1.98)$ with minimum IOL power (18.52) and maximum IOL power $(+22.48)$.

Also, the mean lens thickness in group I was $(4.02 \pm 0.75)$ with a minimum of (3.27) and maximum of (4.77). While in group II was $(4.17 \pm 0.44)$ with a minimum of (3.73) and a maximum of (4.61). Mean postoperative refraction spherical equivalent of the patient in group I was $(-0.65 \pm 0.49)$ in group I: with minimum postoperative refraction spherical equivalent (-0.16) and maximum postoperative refraction spherical equivalent (-1.14). and in group II was $(-0.36 \pm 0.27)$ with minimum postoperative refraction spherical equivalent (-.09) and maximum postoperative refraction spherical equivalent $(-0.63)$, as shown in (table 3).
Table (3): Implanted intraocular lens power, Lens thickness, and actual postoperative spherical Equivalent distribution of both groups.

\begin{tabular}{|c|c|c|c|c|}
\hline \multirow[t]{2}{*}{ Item } & $\begin{array}{c}\text { Group } 1 \\
(n=50)\end{array}$ & $\begin{array}{c}\text { Group } 2 \\
(n=50)\end{array}$ & \multirow[t]{2}{*}{$\mathbf{t}$} & \multirow[t]{2}{*}{ p } \\
\hline & $\mathbf{N}$ & $\%$ & & \\
\hline $\begin{array}{l}\text { Implanted } \\
\text { IOL Power } \\
\text { - Range } \\
\text { - Mean } \pm \text { SD }\end{array}$ & $\begin{array}{c}16.29: \\
21.43 \\
18.86 \pm \\
2.57\end{array}$ & $\begin{array}{c}18.52: \\
+22.48 \\
20.5 \pm \\
1.98\end{array}$ & $\begin{array}{l}3.5 \\
75\end{array}$ & $\begin{array}{c}0.00 \\
1 *\end{array}$ \\
\hline $\begin{array}{l}\text { Lens } \\
\text { thickness } \\
\text { Mean } \pm \text { SD }\end{array}$ & $\begin{array}{c}4.02 \pm \\
0.75\end{array}$ & $\begin{array}{c}4.17 \pm \\
0.44\end{array}$ & $\begin{array}{l}1.1 \\
80\end{array}$ & $\begin{array}{c}0.24 \\
1\end{array}$ \\
\hline $\begin{array}{l}\text { Actual } \\
\text { postoperativ } \\
\text { e SE } \\
\text { - Range } \\
\text { - Mean } \pm \text { SD }\end{array}$ & $\begin{array}{c}(-0.16-- \\
1.16) \\
-0.65 \pm \\
0.49\end{array}$ & $\begin{array}{c}\left(-0.16 \_-\right. \\
1.16) \\
-0.65 \pm \\
0.49\end{array}$ & $\begin{array}{l}3.5 \\
93\end{array}$ & $\begin{array}{c}0.00 \\
1 *\end{array}$ \\
\hline
\end{tabular}

IOL: Intraocular lens $\quad$ SE: Spherical Equivalent

\section{DISCUSSION}

Intraocular lens (IOL) counting is an important step in achieving the desired target refractive outcome, which is a master aim of modern cataract surgery. Numerous devices and formulae are currently available, allowing accurate determination of the IOL power needed to reach target refraction ${ }^{(1,}$ 2). The refractive strength of the human eye builds on: The strength of the cornea keratometry $(\mathrm{K})$ values and the lens, the length of the eye axial length (AL), and the position of the lens ${ }^{(7)}$. Accurate assessment of these variables is essential in achieving optimal postoperative refractive results. If these biometric measurements and calculations are inaccurate, the patients may be left with a significant refractive error (1). To achieve the most favorable outcomes, precise preoperative computation is indispensable and an accurate IOL power formula must be used. A previous study of ultrasound (US) biometry reported that $54 \%$ of the errors in predicted refraction after IOL implantation can be attributed to errors in $\mathrm{AL}$ measurements, $8 \%$ to keratometric error, and $38 \%$ to incorrect assessment of the postoperative effective lens position $(\mathrm{ELP})^{(\mathbf{8})}$. The IOL master utilizes a noncontact technique for AXL measurements which measures the distance between the anterior corneal surface and the retinal pigment epithelium. On the inversion, A-scan biometry measures the range from the corneal vertex to the internal limiting membrane (ILM). Due to the width of the cell layer, the resulting differences of the measured AXL are between 150 and $350 \mathrm{~m}{ }^{(9)}$. IOL master biometry has better accuracy than ultrasound biometry due to it is measures the ocular AXL along the visual axis, as the patient fixates at the measurement beam, whereas during ultrasound biometry a misalignment between the measured axis and the apparent axis may occur ${ }^{(9)}$. In our study, we tried to evaluate the sensitivity and specificity of Optical Biometry (IOL Master) \& 
Ultrasonic Biometry In measuring IOL.

In our study which included 100 eyes of one hundred patients (eyes in 62 females) $(62 \%)$ and (eyes in 38 males) (38\%) with axial lengths less than $25.0 \mathrm{~mm}$ with cataract as the only ocular pathology. Postoperative Visual and Refractive outcome out of 100 patients, 50 were implanted IOL calculated by IOLM and 50 by ultrasound. For IOLM patients 48 (96.0\%) had postoperative spherical refraction in the range of 0.50 to 0.50 and $2(4.0 \%)$ were outside this range. For ultrasonic patients, $40(80.0 \%)$ had postoperative spherical refraction in the range of 0.50 to 0.50 and $10(20.0 \%)$ were outside this range.

In our study, we used the Haggis formula (a fourth-generation formula) to IOL power calculation in the A-scan guided biometry device and the IOL Master device for biometry, which give the best refractive outcomes due to its inclusion of the IOL Master-measured anterior chamber depth (ACD) ${ }^{(\mathbf{1 0})}$. Third-generation formulae such as the Hoffer Q and $\mathrm{SRK} / \mathrm{T}$ are 2-variable formulae that rely on AL and central corneal power to predict the postoperative IOL position. These formulae do not use actual measurements of the ACD; they assume that short eyes will have shallower ACDs and long eyes will

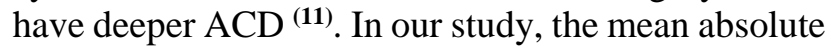
prediction error of optimized IOL Master biometry was significantly smaller $(\mathrm{P}<0.0001)$ than that of optimized ultrasound. In our study, the improvement in the refractive outcome of $16 \%$ was noticed. In Shah et al. ${ }^{(12)}$ the mean absolute prediction error of optimized IOL Master biometry was significantly smaller $(\mathrm{P}<0.0001)$ than that of optimized ultrasound and an improvement in the refractive results of $23 \%$ was noticed. Drexler $\boldsymbol{e t}$ al. ${ }^{(13)}$ and Hitzenberger $\boldsymbol{e t}$ al. ${ }^{(\mathbf{1 4})}$ reported an improvement regarding $30 \%$ when the SRK II formula was used and Rajan et al. ${ }^{(15)}$ reported a $16 \%$ improvement on retrospective IOL power calculations using the IOL Master (16, 17). Contrary to our study, Gantenbein et al. ${ }^{(18)}$ Drexler et $\boldsymbol{a l} .{ }^{(13)}$ set up high precision and reproducibility with both methods postoperatively compared to the preoperative aim $(\mathrm{P}<0.001)$. There was no statistical difference in the mean absolute error between the two groups. Nevertheless, despite the improvement of the refractive outcome, outliers still exist. This may be due to various cataract characteristics, as the IOL Master utilizes the same group refractive index for all cataract grades. IOL Master Biometry was found to be more accurate in the measurement of the ocular axial length than applanation.

\section{CONCLUSION}

We can conclude that IOL measurements performed with the Zeiss IOL Master, using partial coherence interferometry, yielded significantly best IOL power prediction and therefore refractive results in cataract surgery than Applanation US biometry.

\section{REFERENCE}

1. Olsen T (2007): Calculation of intraocular lens power: a review. Acta Ophthalmological Scandinavica, 85(5): 472-485.

2. Jin H, Holzer M, Rabsilber T (2010): Intraocular lens power calculation after laser refractive surgery: a corrective algorithm for corneal power estimation. Journal of Cataract \& Refractive Surgery, 36(1): 87-96.

3. Tappeiner C, Rohrer K, Frueh B et al. (2010): Clinical comparison of biometry using the non-contact optical low coherence reflectometer (Lenstar LS 900) and contact ultrasound biometer (Tomey AL-3000) in cataract eyes. British Journal of Ophthalmology, 94(5): 666-667.

4. Lee A, Qazi M, Pepose J (2008): Biometry and intraocular lens power calculation. Current Opinion in Ophthalmology, 19(1), 1317.

5. Bezuglyi M, Bezuglaya N, Helich I (2017): Ray tracing in ellipsoidal reflectors for optical biometry of media. Applied Optics, 56(30): 8520-8526.

6. Chia T, Nguyen M, Jung H (2018): Comparison of optical biometry versus ultrasound biometry in cases with the borderline signal-to-noise ratio. Clinical Ophthalmology (Auckland, NZ), 12: 1757.

7. Porter J, Queener H, Lin J et al. (2006): Adaptive optics for vision science: Principles, practices, design, and applications. John Wiley \& Sons. Pp. 591.

8. Iyamu E, Osuobeni E (2012): Age, gender, corneal diameter, corneal curvature, and central corneal thickness in Nigerians with normal intraocular pressure. Journal of Optometry, 5(2): 87-97.

9. Gaballa V (2017): IOL master and A-scan biometry. Delta Journal of Ophthalmology, 12: 1110-9173.

10. Bang S, Edell E, Yu Q et al. (2011): Accuracy of intraocular lens calculations using the IOLMaster in eyes with long axial length and a comparison of various formulas. Ophthalmology, 118(3): 503-506.

11. Shajari M, Kolb C, Petermann K et al. (2018): Comparison of 9 modern intraocular lens power calculation formulas for a quadrifocal intraocular lens. Journal of Cataract \& Refractive Surgery, 44(8): 942-948.

12. Shah M, Shah S, Shah K et al. (2014): Biometry for IOL power calculation, which technology is better optical or acoustic?. Sudanese J Ophthalmol., 6:6-9.

13. Drexler W, Findl O, Menapace S et al. (1998): Partial coherence interferometry: a novel approach to biometry in cataract surgery. American Journal of Ophthalmology, 126(4): 524-534.

14. Hitzenberger C, Drexler W, Dolezal C et al. (1993): Measurement of the axial length of cataract eyes by laser Doppler interferometry. Investigative Ophthalmology \& Visual Science, 34(6): 1886-1893.

15. Rajan M, Keilhorn I, Bell J (2002): Partial coherence laser interferometry vs conventional ultrasound biometry in intraocular lens power calculations. Eye, 16(5): 552-556.

16. Shammas H (1984): A comparison of immersion and contact techniques for axial length measurement. American Intra-Ocular Implant Society Journal, 10(4): 444-447.

17. Findl O, Drexler W, Menapace $\mathrm{R}$ et al. (2001): Improved prediction of intraocular lens power using partial coherence interferometry. Journal of Cataract \& Refractive Surgery, 27(6): 861-867.

18. Gantenbein $C$, Lang $H$, Ruprecht $K$ et al. (2003): First steps with the Zeiss IOL Master: A comparison between acoustic contact biometry and non-contact optical biometry. Klinische Monatsblatter fur Augenheilkunde, 220(5): 309-314.

19. Farahat $H$, Ahmed $K$, Marey $H$ et al. (2017). Intraocular lens master optical biometry versus conventional ultrasound biometry in intraocular lens power calculations in highly myopic eyes. Menoufia Medical Journal, 30(2): 485-492. 